\title{
Biodistribution of newly synthesized PHEA-based polymer-coated SPION in Sprague Dawley rats as magnetic resonance contrast agent
}

\author{
This article was published in the following Dove Press journal: \\ International Journal of Nanomedicine \\ 30 October 2013 \\ Number of times this article has been viewed
}

\author{
Junsung Park ${ }^{1,2, *}$ \\ Wonkyung Cho, $1,2, *$ \\ Hee Jun Park ${ }^{1,2}$ \\ Kwang-Ho Cha ${ }^{1,2}$ \\ Dae-Chul Ha ${ }^{2,5}$ \\ Youn-Woong Choi ${ }^{5}$ \\ $\mathrm{Ha}$-Young $\mathrm{Lee}^{3}$ \\ Sun-Hang Cho ${ }^{5}$ \\ Sung-Joo Hwang ${ }^{1,4}$ \\ 'Yonsei Institute of Pharmaceutical \\ Sciences, Yonsei University, Incheon, \\ Republic of Korea; ${ }^{2}$ College of \\ Pharmacy, Chungnam National \\ University, Daejeon, Republic of \\ Korea; ${ }^{3}$ Biomaterials Laboratory, \\ Korea Research Institutes of Chemical \\ Technology, Daejeon, Republic of \\ Korea; ${ }^{4}$ College of Pharmacy, Yonsei \\ University, Incheon, Republic of Korea; \\ ${ }^{5}$ Korea United Pharm Inc, Seoul, \\ Republic of Korea \\ *These authors contributed equally \\ to this work
}

\begin{abstract}
Objectives: The purpose of this study was to observe the pharmacokinetic behavior of newly synthesized biocompatible polymers based on polyhydroxyethylaspartamide (PHEA) to be used to coat an iron oxide core to make superparamagnetic iron oxide nanoparticles (SPION).

Materials and methods: The isotopes $\left[{ }^{14} \mathrm{C}\right]$ and $\left[{ }^{59} \mathrm{Fe}\right]$ were used to label the polymer backbone (CLS) and iron oxide core (FLS), respectively. In addition, unradiolabeled cold superparamagnetic iron oxide nanoparticles (SPION/ULS) were synthesized to characterize particle size by dynamic light scattering, morphology by transmission electron microscopy, and in vivo magnetic resonance imaging (MRI). CLS and FLS were used separately to investigate the behavior of both the synthesized polymer and [Fe] in Sprague Dawley (SD) rats, respectively. Because radioactivity of the isotopes was different by $\beta$ for CLS and $\gamma$ for FLS, synthesis of the samples had to be separately prepared.

Results: The mean particle size of the ULS was $66.1 \mathrm{~nm}$, and the biodistribution of CLS concentrations in various organs, in rank order of magnitude, was liver $>$ kidney $>$ small intestine $>$ other. The biodistribution of FLS concentrations was liver $>$ spleen $>$ lung $>$ other. These rank orders show that synthesized SPION mainly accumulates in the liver. The differences in the distribution were caused by the SPION metabolism. Radiolabeled polymer was metabolized by the kidney and excreted mainly in the urine; $\left[{ }^{59} \mathrm{Fe}\right]$ was recycled for erythrocyte production in the spleen and excreted mainly in the feces. The MR image of the liver after intravenous injection demonstrated that [Fe] effectively accumulated in the liver and exhibited high-contrast enhancement on T2-weighted images.
\end{abstract}

Conclusion: This newly synthesized, polymer-coated SPION appears to be a promising candidate for use as a liver-targeted, biocompatible iron oxide MR imaging agent.

Keywords: SPION, radiolabeled, polyhydroxyethylaspartamide, pharmacokinetic, liver

\section{Introduction}

The field of molecular imaging has been gaining interest in the research world, likely because it enables researchers to visualize the internal structures of the body in great detail. Molecular imaging may even identify altered molecular profiles or cell behavior prior to visual anatomic alterations. There are several molecular imaging techniques known as the "noninvasive, quantitative, and repetitive imaging of targeted macromolecules and biological processes in living organisms." These imaging techniques include magnetic resonance imaging (MRI), computed tomography (CT), positron emission tomography (PET) and X-ray imaging. ${ }^{2} \mathrm{MRI}$ provides good contrast between the
Correspondence: Sung-Joo Hwang College of Pharmacy, Yonsei University, I62-I, Songdo-dong, Yeonsu-gu, Incheon, 406-840, Republic of Korea

$\mathrm{Tel}+82327494518$

Fax +82 327494105

Email sjhII@yonsei.ac.kr 
different soft tissues of the body such as the brain, muscles, heart, and tumors in comparison to other medical imaging techniques such as CT and X-rays. Using MRI contrast agents can increase diagnostic accuracy and imaging sensitivity for detecting pathological changes, and also provide previously undetectable physiological information. ${ }^{3,4}$ There are several types of MRI contrast agents, including gadolinium (III) (Gd) complexes, superparamagnetic iron oxide (SPION) iron platinum, and manganese. Gd-containing MRI contrast agents are most commonly used for the enhancement of vessels in MR angiography and for brain tumor enhancement associated with the degradation of the blood-brain barrier. Gd has a large magnetic moment due to its unpaired electrons, ${ }^{5}$ which increase 1/T1 (longitudinal relaxation rate of water protons) and 1/T2 (transverse rate) by similar amounts; however, the percentage change in $1 / \mathrm{T} 1$ is greater than that in $1 / \mathrm{T} 2 .{ }^{6}$ As a result, Gd is best visualized using T1-weighted images. Boudreau et $\mathrm{al}^{7}$ found that the Gd complex accumulated mostly in the kidneys and, therefore, is not recommended for use in liver imaging. SPION has been classified as biocompatible because it is processed by cells as part of the physiological iron metabolism, has good chemical stability, and is mainly distributed to the liver when it is phagocytosed or endocytosed by the reticuloendothelial system (RES) of the liver. ${ }^{8}$ SPION has better magnetic responsiveness and requires only nanomolar concentrations to produce good images, whereas Gd-based MRI agents need at least millimolar concentrations. ${ }^{9-12}$ To synthesize SPION, many coating materials, including dextran, ${ }^{13,14}$ carboxymethylated dextran, ${ }^{15}$ carboxydextran, ${ }^{16}$ silicon, PEGylated starch, ${ }^{17}$ sulfonated styrene-divinylbenzene copolymer, and citrate, are used to prevent destabilization and agglomeration of the colloidal suspension of iron oxide magnetic nanomaterials. ${ }^{18}$ Among these approaches, currently there are only three types of SPIONs used for the medical imaging: 1) Feridex IV, which is no longer available (Berlex Laboratories, Inc [now Bayer HealthCare Pharmaceuticals, Montville, NJ, USA] has stopped manufacturing it); 2) Resovist ${ }^{\circledR}$ (Schering AG, Berlin, Germany) for detection of significant liver lesions; and 3) ferumoxtran-10 (Combidex; no longer manufactured by AMAG Pharmaceuticals, Lexington, MA, USA), which is more suitable for lymph node imaging.

To prolong plasma half-life in this study, amphiphilic graft derivatives of polyhydroxyethylaspartamide (PHEA) were created to coat the iron oxide core by introducing hydrophobic hexadecylamine and ethanolamine. This extends the circulation time of the particulates from minutes to hours, thereby increasing the targeting capabilities of the contrast agent. ${ }^{19}$ As a drug carrier, PHEA has good biopharmaceutical properties, such as high water solubility, multifunctionality, and low production cost. ${ }^{20-27}$ According to Jeong et al, ${ }^{25}$ PHEA appeared promising as an MRI agent coating material; however, PHEA has not previously been used as an iron oxide MRI agent. Therefore, it is very important to evaluate the pharmacokinetic behavior of the polymer and [Fe] and the in vivo MR imaging capability in the liver. To do so, this study used a rat model and the radiolabeled materials $\left[{ }^{14} \mathrm{C}\right]$ and $\left[{ }^{59} \mathrm{Fe}\right]$, to separately track the polymer and $[\mathrm{Fe}]$, respectively, to observe the pharmacokinetic behavior of the newly synthesized PHEA-based polymer-coated SPION as a new liver targeting MRI agent.

\section{Materials and methods Chemicals}

Poly(succinimide) (PSI) 10,000-11,000 molecular weight was obtained from Baypure ${ }^{\circledR}$ DSP (Leverkusen, Germany), and 1-hexadecylamine, ethanolamine, N,N-dimethylformamide (DMF), ferrous chloride tetrahydrate, ferric chloride hexahydrate, and ammonium hydroxide, were purchased from Sigma-Aldrich (St Louis, MO, USA). Radiolabeled ethanolamine $\left(\left[1-{ }^{14} \mathrm{C}\right]-, 250 \mu \mathrm{Ci}\right)$ was purchased from Moravek Biochemicals Inc (Brea, CA, USA). Hionic-Fluor (a liquid scintillation cocktail), Solvable ${ }^{\circledR}$, and radiolabeled ferric chloride ([$\left.{ }^{59} \mathrm{Fe}\right]-, 500 \mu \mathrm{Ci}$, half-life: 44.6 days) were purchased from PerkinElmer (Branford, CT, USA). All other chemicals were reagent grade.

\section{Animals}

Male and female Sprague Dawley (SD) rats weighing about $250 \mathrm{~g}$ were purchased from SAMTAKO Co, Ltd (Osan, Republic of Korea) for pharmacokinetic studies. Male SD rats weighing about $250 \mathrm{~g}$ were also purchased from Daehan Biolink Co, Ltd (Chungcheongbuk-Do, Republic of Korea) for in vivo MR imaging. Standard deviations for individual body weights within each study were within $\pm 10 \mathrm{~g}$ from the mean body weight of each sex. The mean body weights for each sex group were not statistically different at the $5 \%$ probability level. In pharmacokinetic studies, rats were divided into groups of five according to the time intervals at which the samples were analyzed. The animals were kept in polypropylene cages before and after dosing. A certified rodent pellet diet and pure drinking water were provided under controlled conditions of temperature $\left(22^{\circ} \mathrm{C} \pm 2^{\circ} \mathrm{C}\right)$, relative humidity $(55 \% \pm 5 \%)$ and light $(12$ hours of light and dark). For excretion studies, male and female SD rats were housed in polyethylene metabolism cages (Miraestc, 
Daejeon, Republic of Korea). The animal experiments using rats were performed in compliance with guidelines prescribed by the Chungnam National University (Dajeon, Republic of Korea) Animal Ethical Committee.

\section{Chemicals and reagents} Synthesis of SPION suspension

The procedure for synthesizing the SPION suspension was established and patented by Cho et al. ${ }^{28}$ Unradiolabeled cold-SPION (ULS), $\left[{ }^{14} \mathrm{C}\right]$-labeled SPION (CLS), and $\left[{ }^{59} \mathrm{Fe}\right]-$ labeled SPION (FLS) were synthesized.

\section{Synthesis of the ULS suspension}

The synthesis of ULS suspension is summarized in Figure 1. PSI ( $1.5 \mathrm{~g})$ was dissolved in DMF $(10 \mathrm{~mL})$, and 1-hexadecylamine $(0.327 \mathrm{mg})$ was also dissolved in DMF $(2 \mathrm{~mL})$. These mixtures were then sonicated and mixed at $70^{\circ} \mathrm{C}$ under $\mathrm{N}_{2}$ purge for a total of 24 hours of agitation. After 24 hours, the mixtures were cooled to room temperature and ethanolamine $(0.749 \mathrm{~mL})$ was added; the mixtures were then continuously agitated for an additional 24 hours. Diethyl ether was used for recrystallization and dried at $50^{\circ} \mathrm{C}$ for 24 hours; the polymer powder ( $1.16 \mathrm{~g})$ was then collected and dissolved in deionized water $(40 \mathrm{~mL})$. Ferrous chloride $(0.0794 \mathrm{~g})$ and ferric chloride $(0.1584 \mathrm{~g})$ were dissolved in deionized water $(40 \mathrm{~mL})$. These two solutions were sonicated

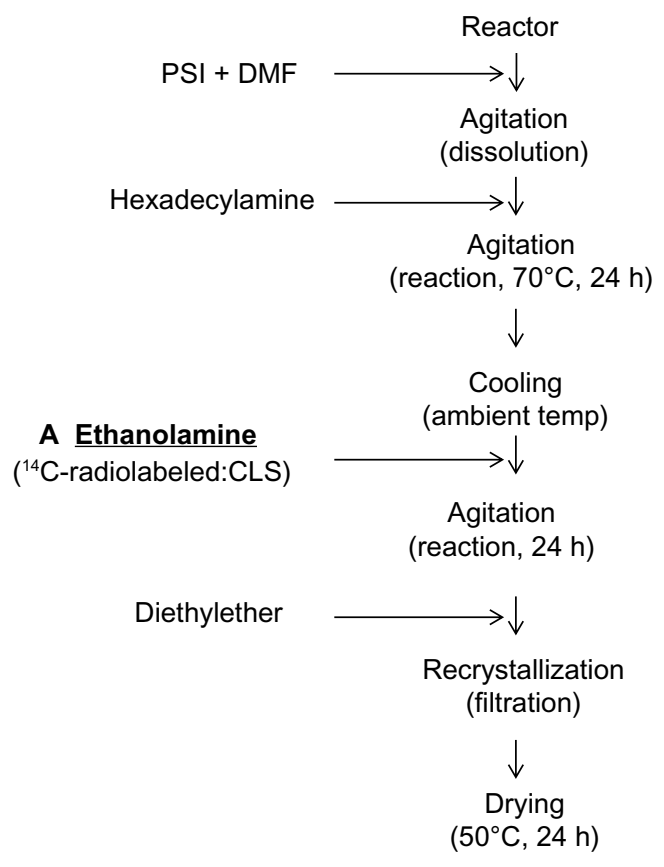

and mixed at $80^{\circ} \mathrm{C}$ under $\mathrm{N}_{2}$ purge until the mixture turned yellowish brown. Then, $3 \mathrm{~mL}$ of $\mathrm{NH}_{4} \mathrm{OH}(\sim 28 \%$ in water) was added to this solution with a 22 gauge needle for 20 minutes, and afterwards the injection reaction was maintained for an additional 40 minutes. At this time, the $\mathrm{pH}$ of the mixture became strongly basic and the color changed to dark brown, indicating the formation of iron oxide particles. To remove the remaining salt and base from the solution, dialysis was performed for 24 hours. After dialysis, deionized water was added, to yield a total volume of $130 \mathrm{~mL}$. The suspension was freeze-dried using Bondiro (Ilshinbiobase, Gyeonggido, Republic of Korea) to obtain the particles, and was then suspended in deionized water prior to use of the final ULS suspension.

\section{Synthesis of the CLS suspension}

The CLS suspension synthesis procedure is summarized in Figure 1. To study the pharmacokinetic behavior of the polymeric backbone, radiolabeled- $\left[{ }^{14} \mathrm{C}\right]$-ethanolamine and cold-ethanolamine were used to synthesize the polymeric backbone (Figure 1A, total ethanolamine: $0.749 \mathrm{~mL}$ ). This labeling procedure was chosen because we were able to obtain a highly radioactive compound through the conjugation of relatively few $\left[{ }^{14} \mathrm{C}\right]$-ethanolamine molecules. Most of the procedures used to synthesize the CLS suspension were the same as those used for the ULS suspension, except
Final product
(SPION suspension)

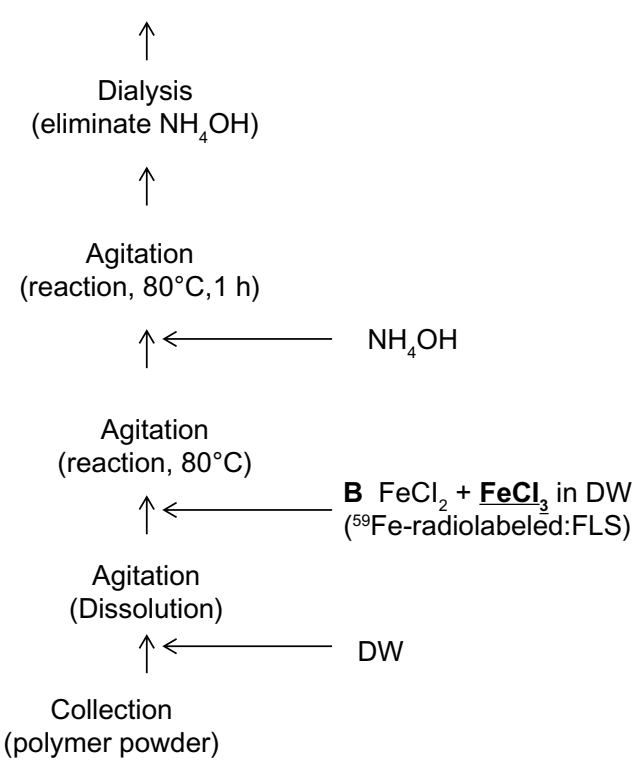

Figure I Scheme of ULS and radiolabeled-SPION suspension synthesis [(A) CLS; (B) FLS].

Abbreviations: h, hours; temp, temperature; SPION, superparamagnetic iron oxide nanoparticles; ULS, unradiolabeled SPION; CLS, [ $\left.{ }^{4} \mathrm{C}\right]$-labeled SPION; FLS, $\left[{ }^{59} \mathrm{Fe}\right]$-labeled SPION; PSI, poly(succinimide); DMF, N,N-dimethylformamide; DW, deionized water. 
that there was no freeze-drying of the CLS suspension. After completing the above procedures, the final CLS suspension was obtained.

\section{Synthesis of the FLS suspension}

The FLS suspension synthesis procedure is summarized in Figure 1. To study the pharmacokinetic behavior of [Fe] in the SPION, radiolabeled-[ $\left.{ }^{59} \mathrm{Fe}\right]$-ferric chloride and coldferric chloride were used (Figure 1B, total ferric chloride: $0.1584 \mathrm{~g}$ ). Most of the procedures used to synthesize the FLS suspension were the same as those used to synthesize the ULS suspension, except that there was no freeze-drying of the FLS suspension. After completing these procedures, the final FLS suspension was obtained.

\section{Particle size analysis}

The mean particle size of the ULS samples was determined by dynamic light scattering (DLS) using an electrophoretic light scattering spectrophotometer (ELS-8000, Otsuka Electronics Co, Ltd, Osaka, Japan). Information about the particle size was obtained by the cumulant method to analyze the DLS data.

\section{Particle morphology}

\section{Transmission electron microscope}

Particle morphology was analyzed by a transmission electron microscope (TEM) (JEOL JEM-2010, Tokyo, Japan). The ULS powder, after being suspended in deionized water, was drop-cast onto a 300-mesh carbon-coated copper grid. The grid was air-dried at room temperature before viewing under the microscope.

\section{Pharmacokinetic studies in SD rats and radiation dosimetry}

Doses of $0.6 \mathrm{~mL}$ of the CLS and FLS suspensions, of which the $[\mathrm{Fe}]$ concentration of the particle suspensions was adjusted to $0.42 \mathrm{mg} / \mathrm{mL}$ and $0.25 \mathrm{mg} / \mathrm{animal}(1 \mathrm{mg} /$ $\mathrm{kg}$ ), respectively, were injected intravenously into the rats' tail veins. This dose is similar to the dose proposed for clinical MRI scans $(1.17 \mathrm{mg} \cdot[\mathrm{Fe}] / \mathrm{kg}) \cdot{ }^{29,30}$ Blood samples were collected from a tail vein different than the one used for injection, according to predetermined time intervals postinjection ( 1 minute, 5 minutes, 10 minutes, 15 minutes, 30 minutes, 1 hour, 2 hours, 4 hours, 12 hours, 1 day, 2 days, 5 days, 10 days, 20 days, 30 days, 50 days). Biodistribution studies were performed by measuring the radioactivity of individual organs, such as the brain, heart, lungs, liver, stomach, small intestine, large intestine, spleen, kidneys, genitals and thigh muscle (inside of the legs) at 0.5 hour, 1 hour, 4 hours, 12 hours, 1 day, 5 days, 10 days, 20 days, 30 days, and 50 days. The digesta was squeezed out of the stomach and intestines. Urine and feces were collected in metabolism cages (with complete and separate collection of feces and urine) for determination of total radioactivity following intravenous administration. The samples were collected at 6 hours, 12 hours, 1 day, 4 days, 8 days, 15 days, 21 days, 28 days, 35 days, 42 days, and 50 days postinjection. At every collection time point, the metabolism cages were washed with $10 \mathrm{~mL} \mathrm{3 \%} \mathrm{H}_{3} \mathrm{PO}_{4}$ solution to detect radioactivity from dried urine in the metabolic cage. Pharmacokinetic parameters were estimated using the K-BE Test 2002 (Korea Food and Drug Administration).

The amount of radioactivity from the samples, in the form of beta or gamma radiation, was determined using the detectors to be described below. The quantitative determination of $\left[{ }^{14} \mathrm{C}\right]$-content was performed using a Packard Tri-Cab 1600 liquid scintillation counter (Packard Instrument Company, Downers Grove, IL, USA). The quantitative determination of the $\left[{ }^{59} \mathrm{Fe}\right]$-content was performed using the WIZARD ${ }^{2 \otimes}$ Automatic Gamma Counter (PerkinElmer).

\section{Sample preparation}

$\left[{ }^{14} \mathrm{C}\right]$-samples (blood, organ, urine,

feces and washings)

A $\left[{ }^{14} \mathrm{C}\right]$-scintillation liquid cocktail was prepared by the following procedures. For the blood samples, $100 \mu \mathrm{L}$ of blood was treated with $1 \mathrm{~mL}$ of Solvable ${ }^{\circledR}$ and kept at $60^{\circ} \mathrm{C}$ for 1 hour until the solution color changed to a greenish brown. After the color change, $0.1 \mathrm{~mL}$ of $0.1 \mathrm{M}$ EDTA-di-sodium and $0.2 \mathrm{~mL}$ of $30 \%$ hydrogen peroxide were added in regular sequence and agitated at room temperature until the color turned light yellow. Then, $10 \mathrm{~mL}$ of scintillation cocktail was added and kept for 1 hour before dosimetry. To obtain organ samples, animals were sacrificed at predetermined time points ( 5 animals per time point) and the organs obtained. The homogenized organ tissue $(200 \mathrm{mg})$ was treated with $2 \mathrm{~mL}$ of Solvable ${ }^{\circledR}$, kept at $50^{\circ} \mathrm{C}$ in a shaking water bath until all the tissue had dissolved, and then cooled to room temperature. Next, $0.2 \mathrm{~mL}$ of $30 \%$ hydrogen peroxide was slowly added and agitated carefully. After agitation, this mixture was kept at $50^{\circ} \mathrm{C}$ in a shaking water bath for 30 minutes, and $10 \mathrm{~mL}$ of scintillation cocktail was added. The mixture was then held for 1 hour before dosimetry. Liquid samples, such as urine, and the liquid collected after washing the cage (washing), were prepared by adding $10 \mathrm{~mL}$ of scintillation cocktail into $1 \mathrm{~mL}$ of urine and washing. 
This mixture was left for 1 hour before dosimetry. To determine the level of radiation in the feces, deionized water was added until the total weight was $80 \mathrm{~g}$ and the mixture was then homogenized. Sodium hypochlorite $(0.5 \mathrm{~mL})$ was added to the $200 \mathrm{mg}$ of homogenized suspension before agitation at $50^{\circ} \mathrm{C}$. The mixture was cooled to room temperature, and the cap was opened for 1 hour to remove the chloride from the suspension. After 1 hour, $10 \mathrm{~mL}$ of scintillation cocktail was added and left for 1 hour before dosimetry. Results for organs, feces and urine with washing were expressed as percentages of the injected radioactivity per organ or per gram of tissue. The blood concentration of the CLS was expressed as $\mu \mathrm{g}$ - equiv/mL ([C]).

[ $\left.{ }^{59} \mathrm{Fe}\right]$-samples (blood, organ, urine, feces and washing)

Blood samples ( $100 \mu \mathrm{L}$ of whole blood) were prepared without any treatment. Organ samples were obtained by sacrifice at predetermined time points ( 5 animals per time point) and whole organs were put into vials to measure radioactivity. Feces, urine, and washing samples were also put into vials and measured without any treatment. Radioactivity was corrected at each time point for $\left[{ }^{59} \mathrm{Fe}\right]$ decay (half-life: 44.6 days). Results for organs, feces and urine with washing were expressed as the percentage of the injected radioactivity per organ or gram of tissue. The blood concentration of $\left[{ }^{59} \mathrm{Fe}\right]$ was expressed as $\mu \mathrm{g}$. equiv $/ \mathrm{mL}([\mathrm{Fe}])$.

\section{In vivo $M R$ imaging test in rats}

In vivo MR imaging studies were performed in male $\mathrm{SD}$ rats with the 3.0-T MRI system (Intera Achieva 3.0T, Philips Healthcare, Best, the Netherlands). T2-weighted MR images of the liver were performed with a fast gradient echo technique. The sequence parameters were $9.6 \mathrm{~ms}$ of repetition time (TR), $4.6 \mathrm{~ms}$ of echo time (TE), 8.0 of flip angle and a $10 \times 5 \mathrm{~cm}^{2}$ field of view (FOV). To get MR images of hepatic contrast, the ULS suspension $(0.5 \mathrm{mg} \cdot[\mathrm{Fe}] / \mathrm{kg})$ was administrated intravenously through the rats' tail vein using a catheter. MR images were taken before injection and at 10 , 20 , and 30 minutes after intravenous administration.

\section{Results and discussion Particle morphology and size}

TEM showed that the average size of large core iron oxide nanoparticles was about $8-10 \mathrm{~nm}$, as illustrated in Figure 2. In aqueous solution, the colloidal particles had a hydrodynamic diameter of about $66.1 \mathrm{~nm}$, determined by DLS measurement. The size measured by DLS was larger than

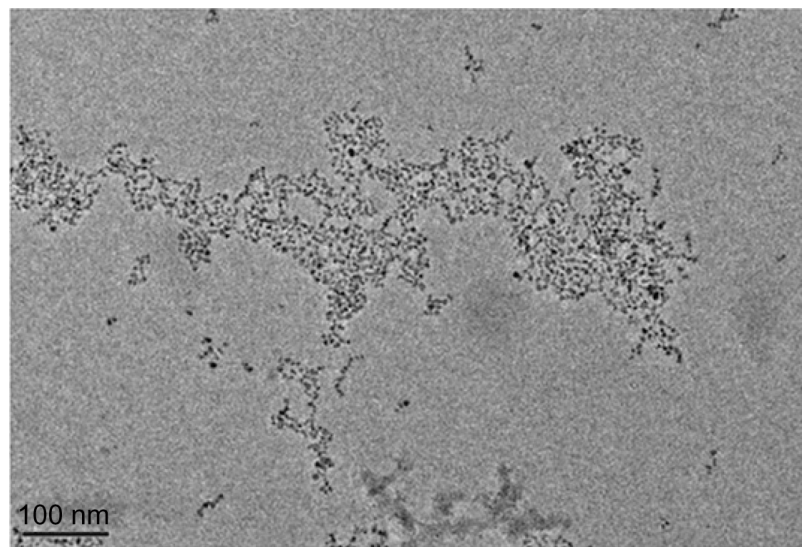

Figure 2 Transmission electron microscopy image of polymer-coated iron oxide nanoparticles.

that measured by TEM; this may be due to the aggregation of the nanoparticles or to the presence of the polymer and hydration layer around the iron oxide nanoparticles in an aqueous solution. Polymer molecules attached to the surface of the iron oxide nanoparticles create steric stabilization of the colloids and cause a repulsive force to separate each nanoparticle.

\section{Biodistribution}

The absorption of CLS and FLS after single intravenous injections, as well as their distribution in various organs, such as the brain, heart, lungs, liver, stomach, small intestine, large intestine, spleen, kidneys, genitals, thigh muscle, and blood, and their excretion in the feces and urine with washing, were determined in male and female SD rats. SD rats were monitored regularly during the pharmacokinetic study period and did not show any signs of behavioral or neurological toxicity.

The time courses for the CLS and FLS biodistribution in SD rats are shown in Figures 3 and 4, respectively. Our results indicate that the injected radiolabeled-SPIONs were widely distributed in many organs. This distribution was not dependent on sex of the rats. At approximately 12 hours postinjection, the highest concentrations of $\left[{ }^{14} \mathrm{C}\right]$ were observed in the liver (about 16\%) and, kidney (about 3.5\%) in both sexes. In order of rank, the small intestine, lung, and spleen followed in terms of $\left[{ }^{14} \mathrm{C}\right]$ concentration; however, other organs showed only negligible changes (Figure 3).

The biodistribution results for the FLS in both sexes demonstrated an $85 \%$ accumulation in the liver and a $3 \%$ accumulation in the spleen, both of which act as a reservoir for erythrocytes. ${ }^{30-34}$ The liver retained more than $80 \%$ of the FLS until day 1 and then decreased to about $60 \%$ within 5 days, a result that was similar for both sexes (Figure 4). This liver 
A

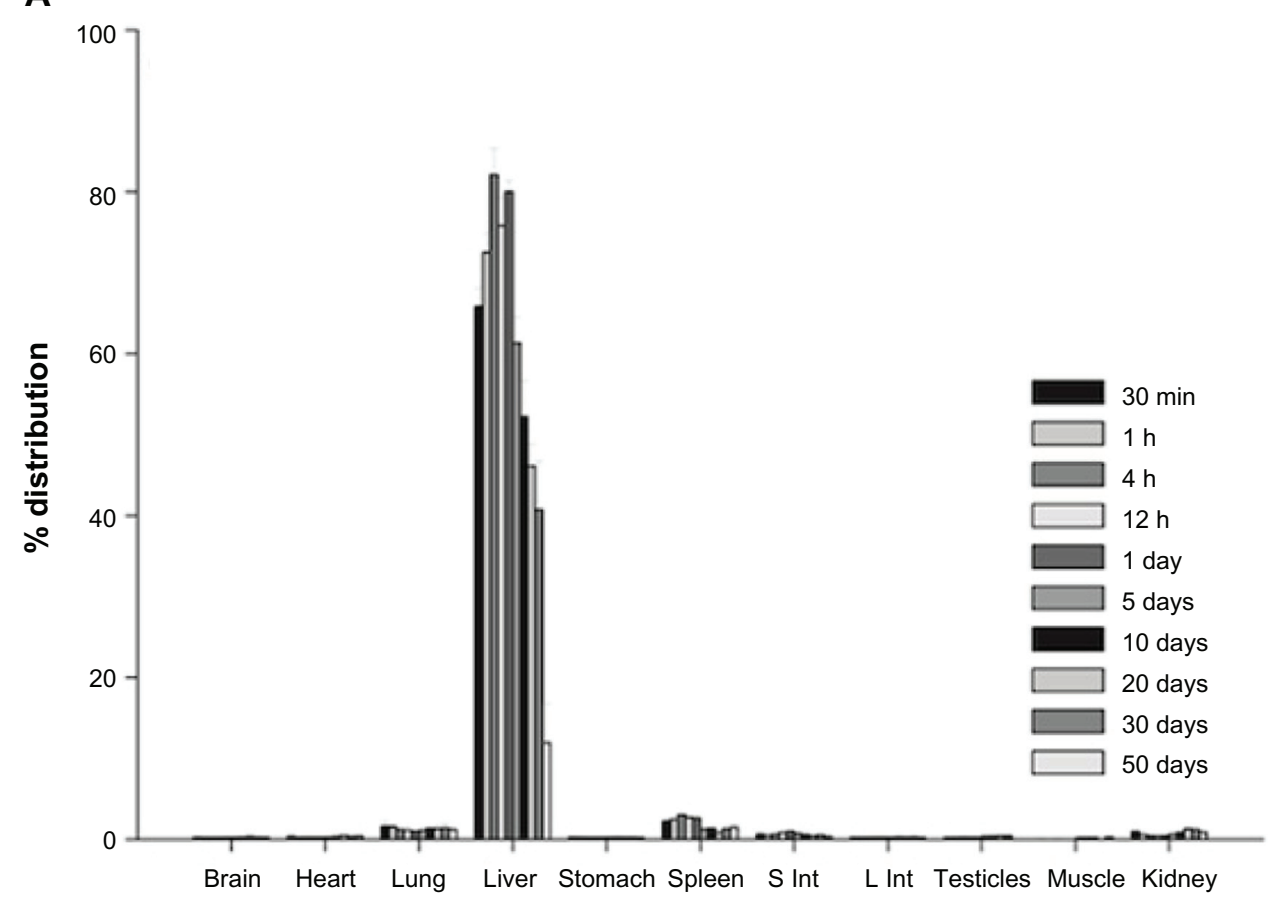

B

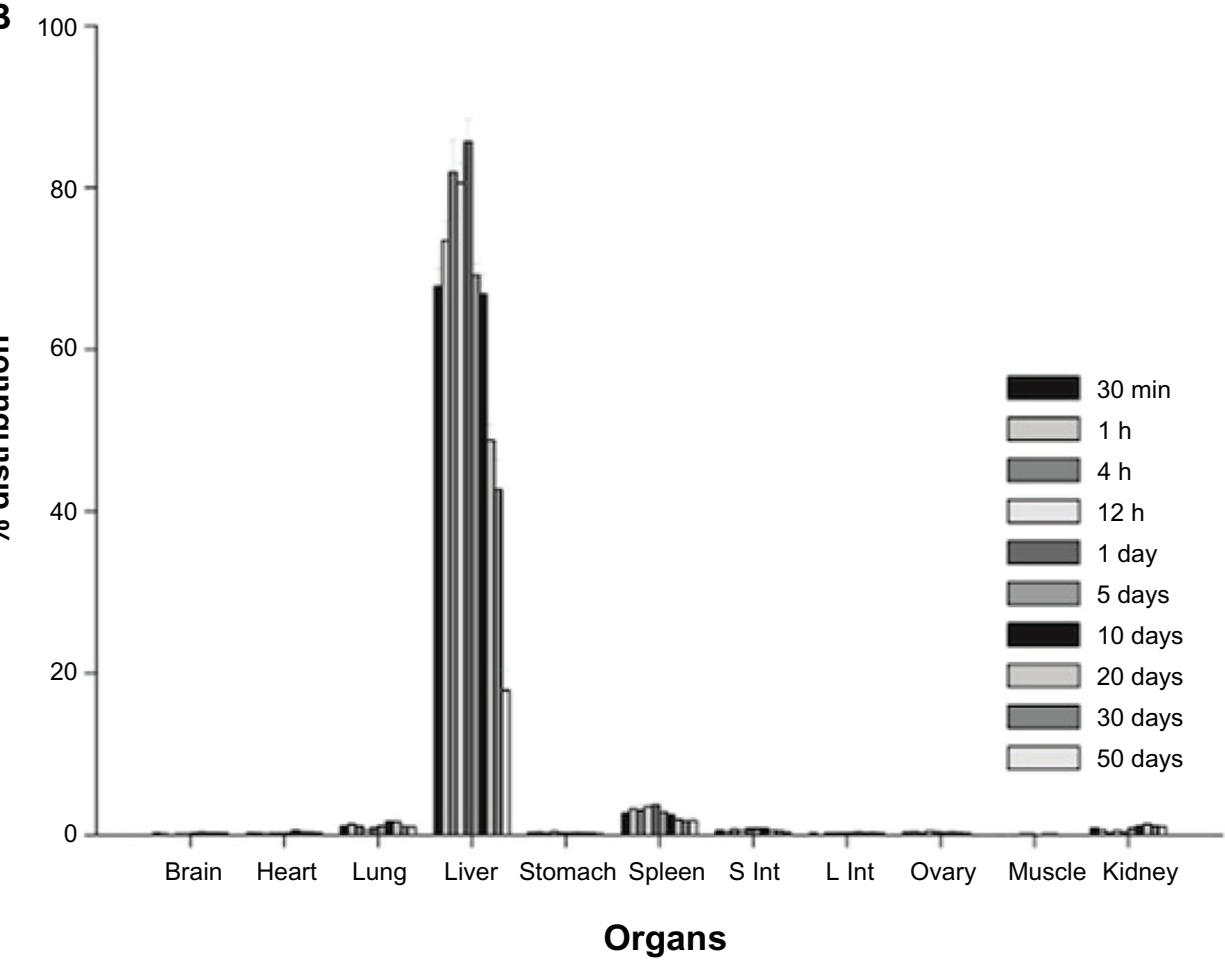

Figure 3 Uptake of the $\left[{ }^{14} \mathrm{C}\right]$ from the $\left[{ }^{14} \mathrm{C}\right]$-labeled SPION by organs at various time points in Sprague Dawley rats $(\mathbf{A})$ male $(\mathbf{B})$ female $(\mathrm{n}=5$ for each sex, mean \pm standard deviation).

Abbreviations: n, number; h, hours; min, minutes; S Int, small intestine; L Int, large intestine; SPION, superparamagnetic iron oxide nanoparticles.

deposition phenomenon is directly related to the function of the mononuclear phagocyte system of the liver, including the Kupffer cells lining the wall of the hepatic sinusoids and the phagocytically active reticulum cells, as well as the large and easily accessible blood supply that passes through the liver where these cells are located. ${ }^{35}$ These cells captured the FLS and led to the accumulation in the respective organs.

The accumulation percentages of CLS and FLS in the main organs (liver, spleen and kidney) are summarized in Table 1. Because the liver is the main organ in which radio- 
A
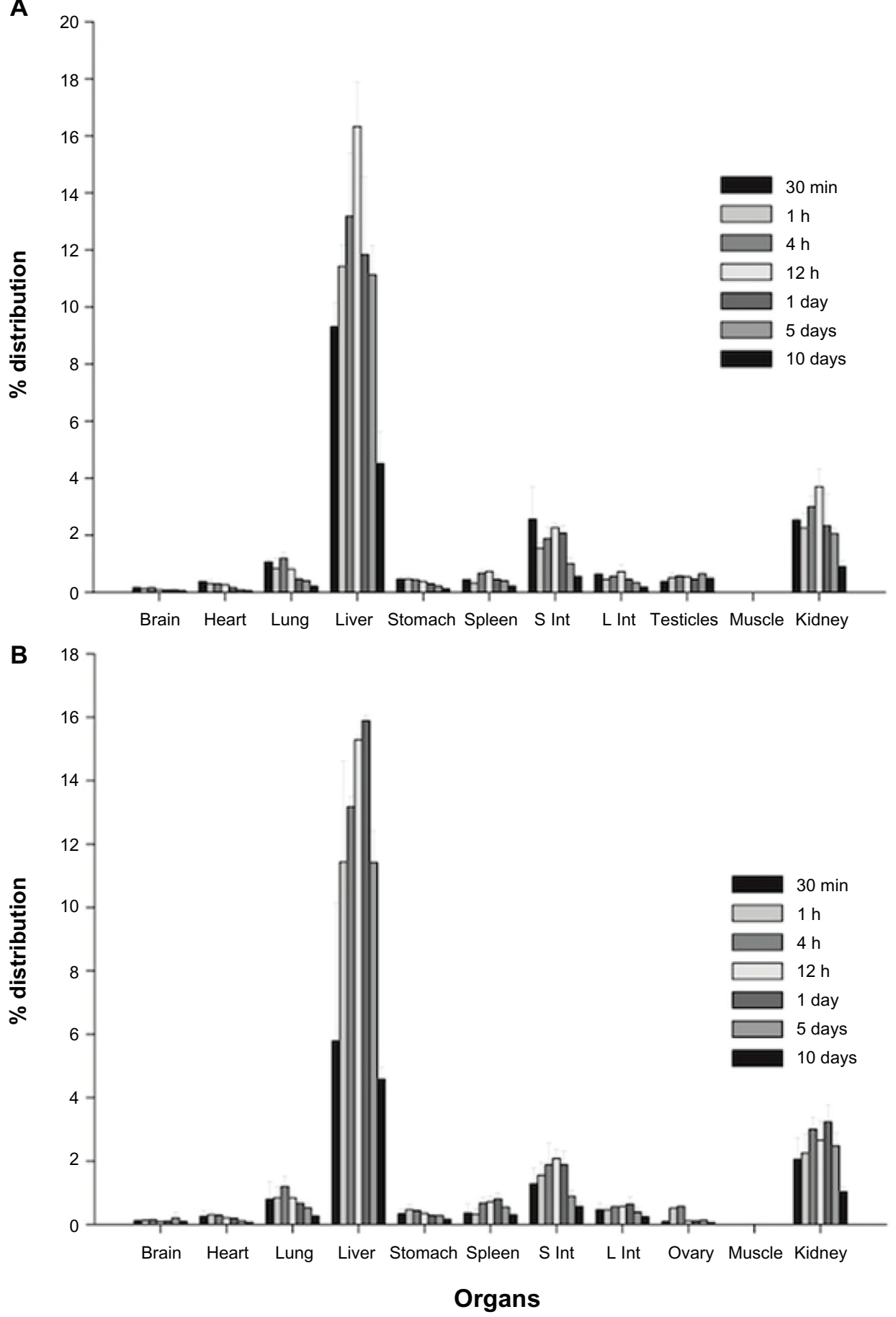

Figure 4 Uptake of the $\left[{ }^{59} \mathrm{Fe}\right]$ from the $\left[{ }^{59} \mathrm{Fe}\right]$-labeled SPION by organs at various time points in Sprague Dawley rats $(\mathbf{A})$ male $(\mathbf{B})$ female $(\mathrm{n}=5$ for each sex, mean \pm standard deviation).

Abbreviations: $\mathrm{n}$, number; h, hours; min, minutes; S Int, small intestine; L Int, large intestine; SPION, superparamagnetic iron oxide nanoparticles.

labeled-SPION accumulates, its pharmacokinetic parameters were obtained and are summarized in Table 2. The maximum concentrations of CLS were $16.32 \%$ at 12 hours and $15.89 \%$ at 24 hours. Its half-life in the liver was 6.31 days and 5.02 days for males and females, respectively. The maximum concentrations of FLS in male and female livers at 4 hours were $80.04 \%$ and $85.70 \%$, and the half-life was 21.62 days and 23.40 days for males and females, respectively.

\section{Blood concentration}

Blood concentrations were measured at 1 minute, 5 minutes, 10 minutes, 15 minutes, 30 minutes, 1 hour, 4 hours, 12 hours, 
Table I Average accumulated radioactive material percentage-time profile of 3 main organs of male and female Sprague Dawley rats ( $n=5$ for each sex, mean \pm standard deviation)

\begin{tabular}{|c|c|c|c|c|c|c|}
\hline & \multicolumn{2}{|l|}{ Liver (\%) } & \multicolumn{2}{|l|}{ Spleen (\%) } & \multicolumn{2}{|l|}{ Kidney (\%) } \\
\hline & Male & Female & Male & Female & Male & Female \\
\hline \multicolumn{7}{|c|}{$\left[{ }^{14} \mathrm{C}\right]-S P I O N$} \\
\hline $0.5 \mathrm{~h}$ & $9.31 \pm 0.84$ & $5.79 \pm 4.36$ & $0.44 \pm 0.03$ & $0.36 \pm 0.30$ & $2.54 \pm 0.10$ & $2.06 \pm 0.69$ \\
\hline $\mathrm{I} \mathrm{h}$ & $1 \mathrm{I} .43 \pm 0.74$ & $11.43 \pm 3.20$ & $0.32 \pm 0.13$ & $0.32 \pm 0.17$ & $2.25 \pm 0.52$ & $2.25 \pm 0.60$ \\
\hline $4 \mathrm{~h}$ & $13.18 \pm 2.20$ & $13.18 \pm 0.33$ & $0.67 \pm 0.14$ & $0.67 \pm 0.20$ & $3.00 \pm 0.38$ & $3.00 \pm 0.38$ \\
\hline $12 \mathrm{~h}$ & $16.32 \pm 1.57$ & $15.29 \pm 0.12$ & $0.73 \pm 0.06$ & $0.71 \pm 0.18$ & $3.70 \pm 0.63$ & $2.66 \pm 0.60$ \\
\hline I day & $11.83 \pm 2.74$ & $15.89 \pm 0.17$ & $0.46 \pm 0.15$ & $0.80 \pm 0.19$ & $2.33 \pm 1.14$ & $3.23 \pm 0.55$ \\
\hline 5 days & $11.13 \pm 1.03$ & $11.42 \pm 0.99$ & $0.40 \pm 0.05$ & $0.55 \pm 0.10$ & $2.06 \pm 0.20$ & $2.48 \pm 0.40$ \\
\hline 10 days & $4.51 \pm 1.12$ & $4.58 \pm 0.38$ & $0.22 \pm 0.08$ & $0.30 \pm 0.06$ & $0.90 \pm 0.21$ & $1.03 \pm 0.15$ \\
\hline \multicolumn{7}{|c|}{$\left[{ }^{59} \mathrm{Fe}\right]-\mathrm{SPION}$} \\
\hline $0.5 \mathrm{~h}$ & $65.83 \pm 2.26$ & $67.78 \pm 2.25$ & $2.24 \pm 0.34$ & $2.67 \pm 0.27$ & $0.90 \pm 0.17$ & $0.80 \pm 0.18$ \\
\hline $\mathrm{Ih}$ & $72.53 \pm 2.33$ & $73.47 \pm 2.37$ & $2.44 \pm 0.49$ & $3.20 \pm 0.55$ & $0.58 \pm 0.11$ & $0.57 \pm 0.24$ \\
\hline $4 \mathrm{~h}$ & $82.10 \pm 3.29$ & $81.89 \pm 4.01$ & $3.01 \pm 0.22$ & $3.07 \pm 0.67$ & $0.43 \pm 0.04$ & $0.28 \pm 0.02$ \\
\hline $12 \mathrm{~h}$ & $75.82 \pm 3.42$ & $80.57 \pm 2.53$ & $2.69 \pm 0.44$ & $3.50 \pm 0.42$ & $0.39 \pm 0.03$ & $0.50 \pm 0.34$ \\
\hline I day & $80.04 \pm 1.40$ & $85.68 \pm 2.75$ & $2.58 \pm 0.34$ & $3.70 \pm 0.66$ & $0.43 \pm 0.04$ & $0.34 \pm 0.05$ \\
\hline 5 days & $61.31 \pm 3.23$ & $69.16 \pm 1.53$ & $1.24 \pm 0.17$ & $2.83 \pm 0.58$ & $0.64 \pm 0.14$ & $0.82 \pm 0.28$ \\
\hline 10 days & $52.23 \pm 4.42$ & $66.83 \pm 2.54$ & $1.33 \pm 0.17$ & $2.45 \pm 0.44$ & $0.85 \pm 0.13$ & $1.10 \pm 0.14$ \\
\hline 20 days & $46.09 \pm 2.73$ & $48.75 \pm 1.98$ & $0.87 \pm 0.10$ & $1.88 \pm 0.39$ & $1.29 \pm 0.19$ & $1.33 \pm 0.15$ \\
\hline 30 days & $40.73 \pm 6.00$ & $42.69 \pm 3.66$ & $1.29 \pm 0.55$ & $1.73 \pm 0.35$ & $1.21 \pm 0.35$ & $1.09 \pm 0.24$ \\
\hline 50 days & $11.93 \pm 4.80$ & $|7.87 \pm 2.6|$ & $1.47 \pm 0.34$ & $\mathrm{I} .76 \pm 0.4 \mathrm{I}$ & $0.86 \pm 0.17$ & $0.99 \pm 0.19$ \\
\hline
\end{tabular}

Abbreviations: h, hours; $n$, number; SPION, superparamagnetic iron oxide nanoparticles.

24 hours, 2 days, 5 days, and 10 days for the CLS and at the same time points for the FLS. Additional measurements were performed for the FLS at 20, 30, and 50 days after a single intravenous injection into the tail vein of SD rats. The results are shown in Figures 5 and 6.

Both of the radiolabeled-SPION suspensions in the blood were quickly taken up by liver, kidney and spleen. Less than $10 \%$ remained in the blood after 12 hours. These results agree with those of our previous organ distribution studies. ${ }^{34,36,37}$ The half-lives of CLS and FLS in the blood were about 30 minutes and 15 minutes in both sexes, respectively (Table 3 ).

The concentrations of CLS and FLS in the blood behaved in distinctly different ways. The pharmacokinetic behavior of the CLS fit a bi-compartmental model, indicating that the radiolabeled-polymer undergoes peripheral distribution (Figure 5) ${ }^{38}$ The CLS suspension moved through the blood to

Table 2 Pharmacokinetic parameter obtained by intravenous injection of $\left[{ }^{14} \mathrm{C}\right]-S P I O N$ and $\left[{ }^{59} \mathrm{Fe}\right]-S P I O N$ in the liver of Sprague Dawley rats ( $\mathrm{n}=5$ for each sex, mean \pm standard deviation)

\begin{tabular}{|c|c|c|c|c|}
\hline \multirow[t]{2}{*}{ Liver } & \multicolumn{2}{|c|}{$\left[{ }^{14} \mathrm{C}\right]$-SPION } & \multicolumn{2}{|c|}{$\left[{ }^{59} \mathrm{Fe}\right]-S P I O N$} \\
\hline & Male & Female & Male & Female \\
\hline $\mathrm{T}_{\max }(\mathrm{h})$ & 12 & 24 & 4 & 4 \\
\hline $\mathrm{C}_{\max }(\%)$ & $16.32 \pm 1.57$ & $17.82 \pm 2.04$ & $80.04 \pm 1.40$ & $85.70 \pm 2.71$ \\
\hline $\mathrm{t}_{1 / 2}$ (day) & $6.31 \pm 2.04$ & $5.02 \pm 2.06$ & $21.62 \pm 4.46$ & $23.40 \pm 3.71$ \\
\hline
\end{tabular}

Abbreviations: h, hours; SPION, superparamagnetic iron oxide nanoparticles; n, number. the liver, kidneys, lungs, small intestine and finally the spleen; these organs are primarily responsible for the distribution, metabolism and excretion of exogenous materials. The FLS concentration in the blood was the lowest at 12 hours after injection, a result that was similar for both sexes (Figure 6). However, the FLS showed a different time-blood concentration profile than CLS. The blood concentration of FLS gradually increased until 20 days after injection and then began to decrease. The reason for the increase in $\left[{ }^{59} \mathrm{Fe}\right]$ concentration is the reuse/recycling of $\left[{ }^{59} \mathrm{Fe}\right]$ from the FLS by cells for the normal biochemical pathways of [Fe] metabolism, for example, for erythrocyte production. ${ }^{35,39-43}$ This result correlated well with the decrease in radioactivity in the liver. This concentration-time relationship was confirmed by the lack of radioactivity of $\left[{ }^{59} \mathrm{Fe}\right]$ in the plasma, indicating that the radioactivity of the whole blood was due to corpuscular matter alone. Therefore, we concluded that the $\left[{ }^{59} \mathrm{Fe}\right]$ detected was from the blood cell corpuscles and that it was eliminated very slowly compared with the CLS. The same behavior has been described for the excretion of ferumoxtran-10, iron oxide nanoparticles coated with dextrans..$^{44,45}$

\section{Excretion}

There was no significant difference between sexes in the excretion study. As summarized in Table 4, the total percent of accumulation of $\left[{ }^{14} \mathrm{C}\right]$ and $\left[{ }^{59} \mathrm{Fe}\right]$ as calculated through 


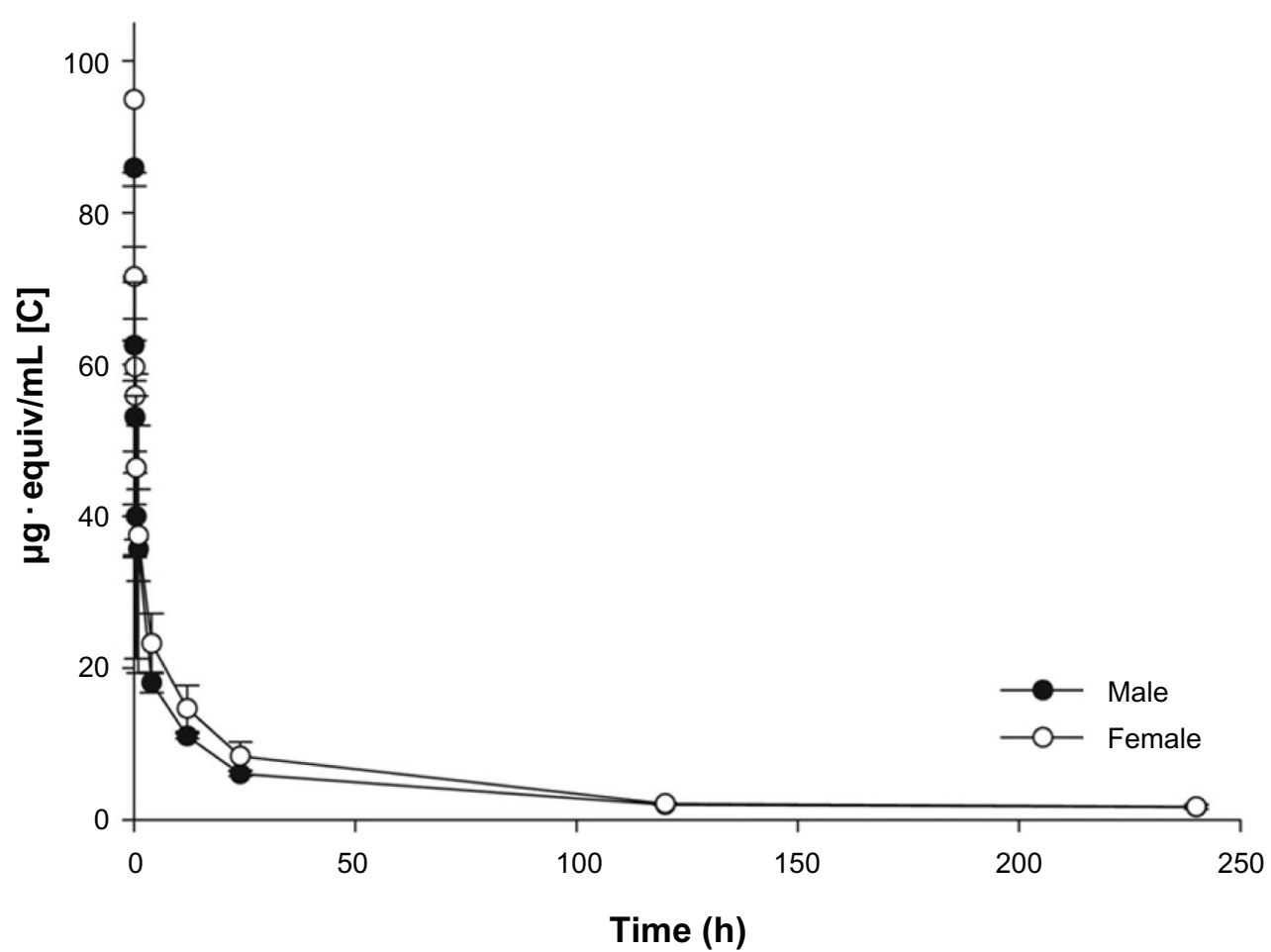

Figure 5 Mean blood concentration-time profiles for the $\left[{ }^{14} \mathrm{C}\right]$ from the $\left[{ }^{14} \mathrm{C}\right]$-labeled SPION in male and female Sprague Dawley rats after administration of intravenous injection ( $n=5$ for each sex, mean \pm standard deviation).

Abbreviations: $\mathrm{n}$, number; $\mathrm{h}$, hours; SPION, superparamagnetic iron oxide nanoparticles.

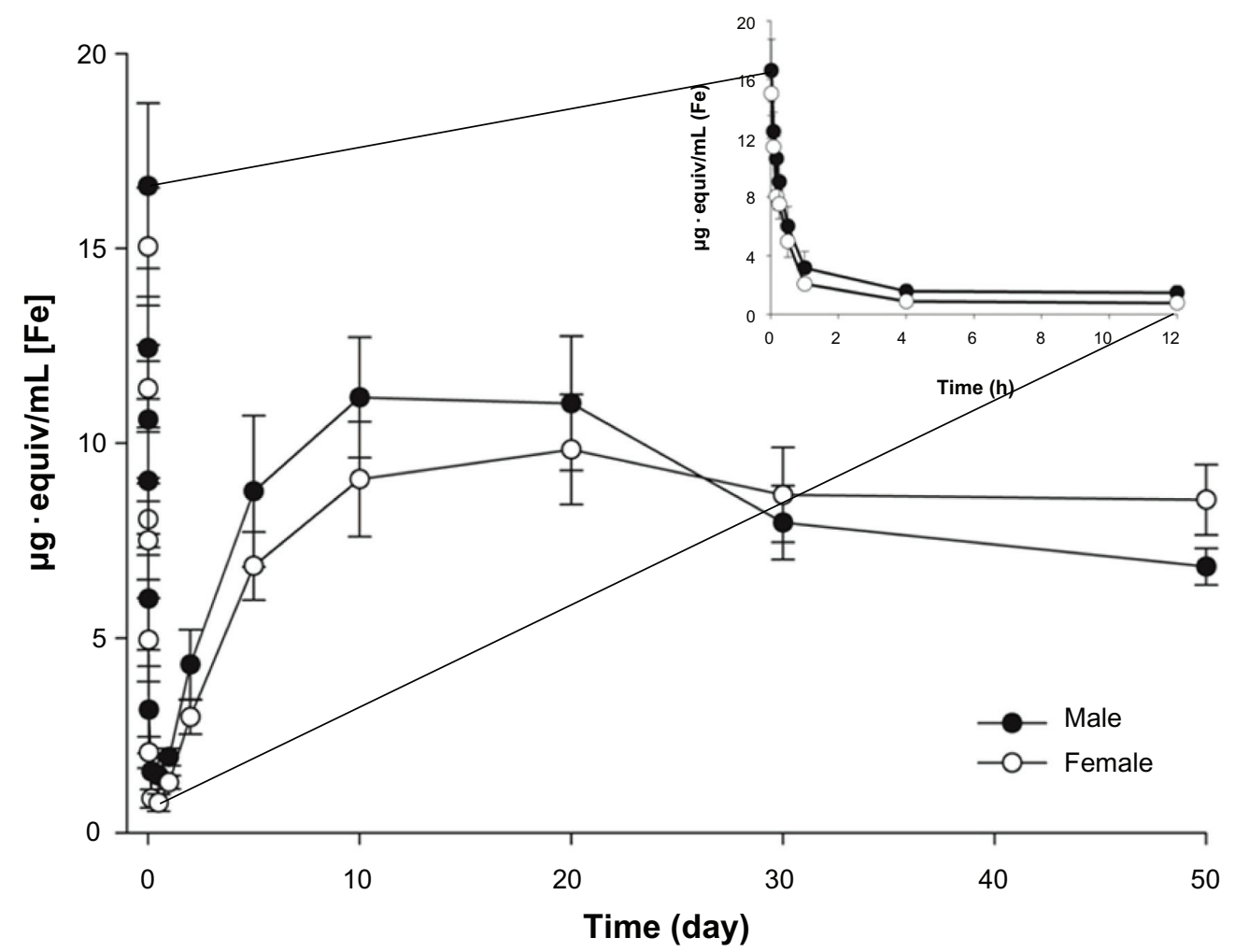

Figure 6 Mean blood concentration-time profiles for the $\left[{ }^{59} \mathrm{Fe}\right]$ from the $\left[{ }^{59} \mathrm{Fe}\right]$-labeled SPION in male and female Sprague Dawley rats after administration of intravenous injection ( $n=5$ for each sex, mean \pm standard deviation).

Abbreviations: $\mathrm{n}$, number; h, hours; SPION, superparamagnetic iron oxide nanoparticles. 
Table 3 The half-life of blood radioactive concentration of $\left[{ }^{14} \mathrm{C}\right]-$ SPION and $\left[{ }^{59} \mathrm{Fe}\right]-S P I O N$ after intravenous injection in male and female Sprague Dawley rats ( $n=5$, mean \pm standard deviation)

\begin{tabular}{llllll}
\hline & {$\left[{ }^{14} \mathrm{C}\right]$-SPION } & & & {$\left[{ }^{59} \mathrm{Fe}\right]$-SPION } \\
\cline { 2 - 3 } \cline { 5 - 6 } & Male & Female & & Male & Female \\
\hline $\mathrm{t}_{1 / 2}(\mathrm{~min})$ & $24.53 \pm 7.42$ & $26.47 \pm 8.1 \mathrm{I}$ & & $15.81 \pm 3.1 \mathrm{I}$ & $\mathrm{I} 4.57 \pm 2.64$ \\
\hline
\end{tabular}

Abbreviations: min, minutes; SPION, superparamagnetic iron oxide nanoparticles; n, number.

excretion after the experiment was about $60 \%$ and $14 \%$ in both sexes, respectively.

Moreover, the main routes of excretion for the CLS and FLS were different. The CLS was mainly excreted by the kidneys. About $37 \%$ was excreted in the urine at the end of the experiment in both sexes, whereas excretion in the feces constituted only about $23 \%$ of the total CLS that was injected. The radioactivity of $\left[{ }^{14} \mathrm{C}\right]$ in the urine peaked at $23 \%$ at $0-6$ hours and thereafter was about excreted at $1 \%-2 \%$ per day (Figure 7).

According to the results of the excretion study, despite significant accumulation in the liver, CLS metabolites did not accumulate in bile for fecal excretion. The material was excreted mainly in the urine, and most was excreted within 6 hours. Therefore, the kidneys showed the secondhighest percentage accumulation of all organs. The urinary excretion and the accumulation of CLS in the kidneys are evidence of renal metabolism. Moreover, the small intestine and lungs, which are the organs responsible for the excretion of carbon from exogenous materials, also had a relatively high accumulation. Even though there was a small amount of fecal excretion, accumulation in the small intestine was noted. Given that the lungs also showed a high accumulation percentage of $\left[{ }^{14} \mathrm{C}\right]$, it is plausible that $\left[{ }^{14} \mathrm{C}\right]$ might be excreted via carbon dioxide by exhalation from the lungs. ${ }^{46}$ Unfortunately, radiation from exhalation was not measured.

The FLS was mainly excreted by the fecal route at a rate of $11 \%$, followed by urinary excretion (about 3\%). Only about $14 \%$ of the injected $\left[{ }^{59} \mathrm{Fe}\right]$ was excreted within 50 days, which is a smaller amount than that of the CLS excretion. Therefore, we hypothesize that there was reuse of $\left[{ }^{59} \mathrm{Fe}\right]$.
Fecal excretion of $\left[{ }^{59} \mathrm{Fe}\right]$ was significantly lower on the first day after the intravenous injection, with the quantity of fecal excretion increasing daily (Figure 8).

The highest excretion of accumulated material occurred at 4-8 days, probably due to the excretion of unneeded $\left[{ }^{59} \mathrm{Fe}\right]$ from the body after the storage of $\left[{ }^{59} \mathrm{Fe}\right]$ in tissues such as the liver, spleen and blood, and also the subsequent destruction of erythrocytes. ${ }^{47,48}$ Under normal conditions, $[\mathrm{Fe}]$ is negligibly excreted in the urine. However, in this study, a large amount of $\left[{ }^{59} \mathrm{Fe}\right]$ was injected in a short time, and radiolabeled $\left[{ }^{59} \mathrm{Fe}\right]$ atoms found their way to the urine. ${ }^{48}$ Since $\left[{ }^{59} \mathrm{Fe}\right]$-excretion in the urine at $21-28$ days suddenly increased to $1 \%$, radioactivity in the blood may have started to decrease after 20 days. These data aid understanding of the general behavior of the newly synthesized polymer-coated SPION in living bodies.

\section{MR images}

Figure 9 shows T2-weighted MR images of the liver of rats $(n=2)$ before and at different time points after injection of the synthesized ULS. These images demonstrate profound negative enhancement of the liver parenchyma after injection of the ULS. The prepared ULS contrast agent, with a size of about $66.1 \mathrm{~nm}$, effectively accumulated in the liver and exhibited high contrast enhancement on T2-weighted images. The signal intensity started increasing as early as 10 minutes after injection and increased gradually up to 30 minutes. These particles were taken up by healthy rat liver, which became dark (arrow) on T2-weighted MR images. We can assume that the synthesize ULS induces significant differences in T2-relaxation time between normal tissue and lesions, resulting in increased lesion conspicuity and detectability.

\section{Conclusion}

We have synthesized a new polymeric backbone based on biocompatible PHEA. We have also demonstrated its pharmacokinetic behavior and produced in vivo MR images of the agent in use in SD rats. Our newly synthesized SPION accumulated mainly in the liver, as confirmed by the in vivo

Table 4 Cumulative excreted amount by percentage of $\left[{ }^{14} \mathrm{C}\right]$ and $\left[{ }^{59} \mathrm{Fe}\right](\mathrm{n}=5$ for each sex, mean \pm standard deviation)

\begin{tabular}{|c|c|c|c|c|c|c|}
\hline & \multicolumn{3}{|l|}{ Male } & \multicolumn{3}{|l|}{ Female } \\
\hline & Feces & Urine & Total & Feces & Urine & Total \\
\hline$\left[{ }^{14} \mathrm{C}\right]$ excretion (\%, 10 days) & $23.2 \pm 0.88$ & $36.82 \pm 2.56$ & $59.84 \pm 2.73$ & $23.73 \pm 0.84$ & $36.77 \pm 2.97$ & $60.51 \pm 3.07$ \\
\hline$\left[{ }^{59} \mathrm{Fe}\right]$ excretion $(\%, 50$ days $)$ & $11.96 \pm 0.21$ & $2.94 \pm 0.05$ & $|4.8| \pm 0.56$ & $10.45 \pm 0.19$ & $2.94 \pm 0.05$ & $13.30 \pm 0.87$ \\
\hline
\end{tabular}

Abbreviation: $n$, number. 


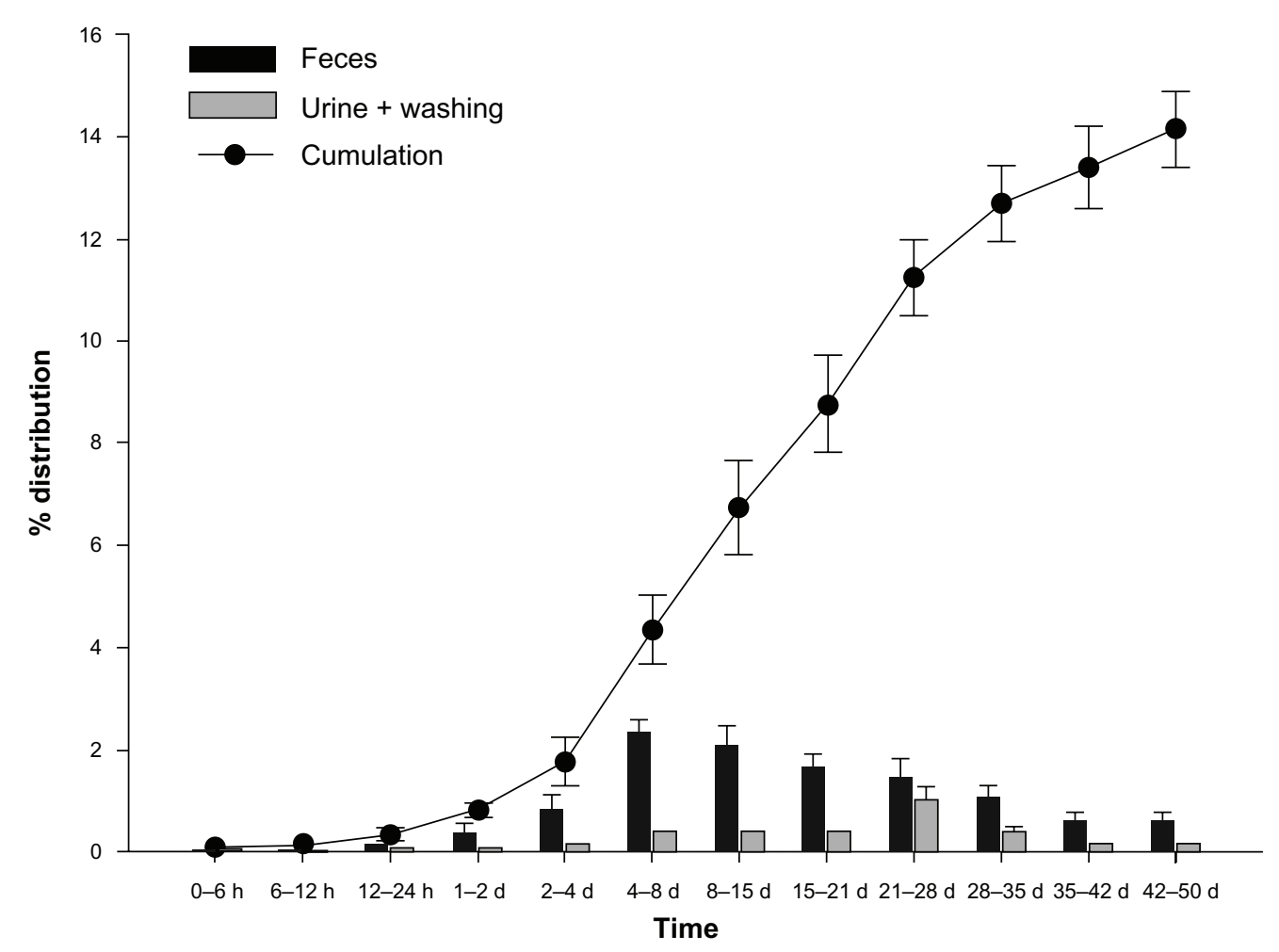

Figure 7 Excretion percentage of the $\left[{ }^{14} \mathrm{C}\right]$ from the $\left[{ }^{14} \mathrm{C}\right]$-labeled SPION at various time points in Sprague Dawley rats ( $\mathrm{n}$ : male $=5$, female $=5$, mean \pm standard deviation). Abbreviations: $n$, number; h, hours; $d$, day; SPION, superparamagnetic iron oxide nanoparticles.

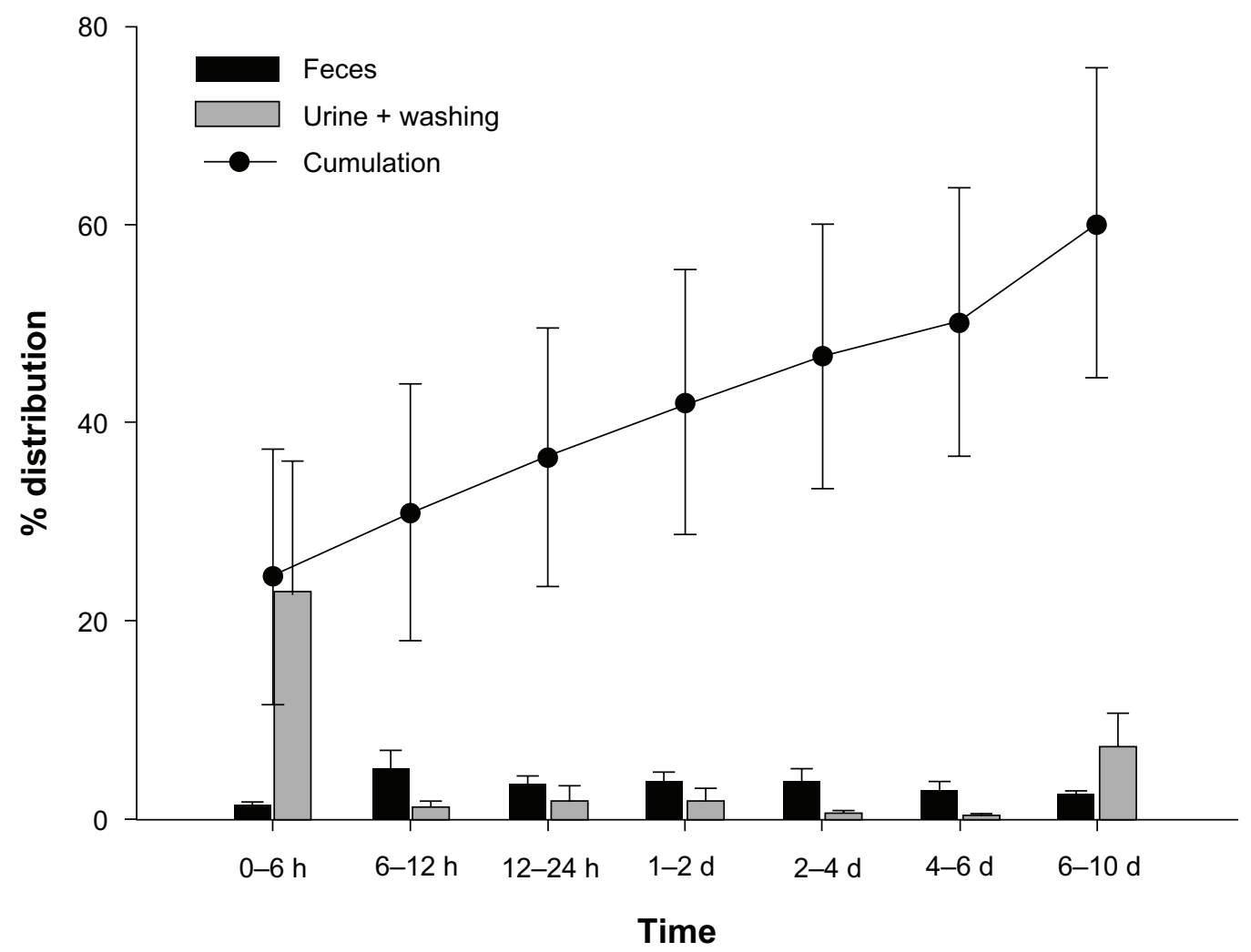

Figure 8 Excretion percentage of the $\left[{ }^{59} \mathrm{Fe}\right]$ from the $\left[{ }^{59} \mathrm{Fe}\right]$-labeled SPION at various time points in Sprague Dawley rats ( $\mathrm{n}: \mathrm{male}=5$, female $=5$, mean $\pm \mathrm{standard} \mathrm{deviation).}$ Abbreviations: $n$, number; h, hours; d, day; SPION, superparamagnetic iron oxide nanoparticles. 

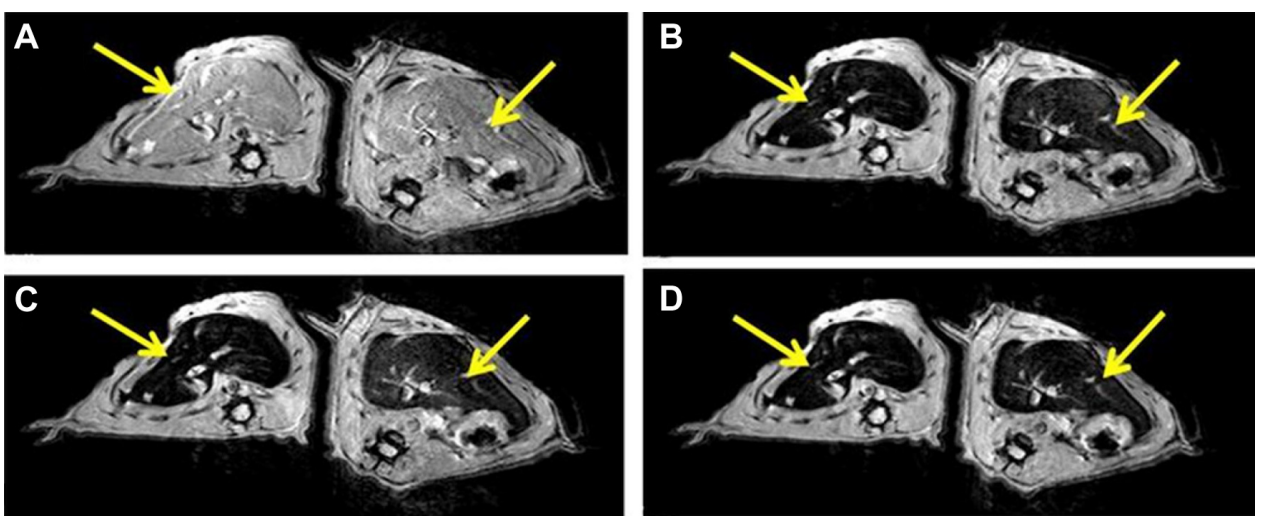

Figure 9 T2-weighted magnetic resonance images of rat livers $(\mathbf{A})$ before injection,

(B) 10 minutes after injection, (C) 20 minutes after injection, (D) 30 minutes after injection of the cold SPION suspension.

Note: The arrows point to the liver.

Abbreviation: SPION, superparamagnetic iron oxide nanoparticle.

distribution study after intravenous injection of the CLS and FLS. In addition, the polymer was metabolized mainly by the kidneys and excreted by the urine within a short time, whereas the $\left[{ }^{59} \mathrm{Fe}\right]$ was excreted in the feces after reuse in erythrocytes. This newly synthesized PHEA-based polymer-coated SPION is a promising candidate for use in liver-targeted biocompatible iron oxide MRI agents.

\section{Acknowledgment}

This work was supported by Korea United Pharm Inc.

\section{Disclosure}

The authors report no conflicts of interest in this work.

\section{References}

1. Roselt P, Meikle S, Kassiou M. The role of positron emission tomography in the discovery and development of new drugs; as studied in laboratory animals. Eur J Drug Metab Pharmacokinet. 2004;29(1):1-6.

2. Herschman HR. Molecular imaging: looking at problems, seeing solutions. Science. 2003;302(5645):605-608.

3. Rosen JE, Yoffe S, Meerasa A, Verma M, Gu FX. Nanotechnology and diagnostic imaging: new advances in contrast agent technology. J Nanomed Nanotechnol. 2011;2(5):115-126.

4. Weissleder R, Hahn PF, Stark DD, et al. Superparamagnetic iron oxide: enhanced detection of focal splenic tumors with MR imaging. Radiology. 1988;169:399-403.

5. Zhu D, White RD, Hardy PA, Weerapreeyakul N, Sutthanut K, Jay M. Biocompatible nanotemplate-engineered nanoparticles containing gadolinium: stability and relaxivity of a potential MRI contrast agent. J Nanosci Nanotech. 2006;6(4):996-1003.

6. Caravan P, Ellison JJ, McMurry TJ, Lauffer RB. Gadolinium(III) chelates as MRI contrast agents: structure, dynamics, and applications. Chem Rev. 1999;99(9):2293-2352.

7. Boudreau RJ, Burbidge S, Sirr S, Loken MK. Comparison of the biodistribution of manganese-54 DTPA and gadolinium-153 DTPA in dogs. $J$ Nucl Med. 1987;28(3):349-353.

8. Müller K, Skepper JN, Posfai M, et al. Effect of ultrasmall superparamagnetic iron oxide nanoparticles (Ferumoxtran-10) on human monocyte-macrophages in vitro. Biomaterials. 2007;28(9):1629-1642.
9. Vogl TJ, Hammerstingl R, Schwarz W, et al. Magnetic resonance imaging of focal liver lesions: comparison of the superparamagnetic iron oxide resovist versus gadolinium-DTPA in the same patient. Invest Radiol. 1996;31(11):696-708.

10. Bulte JW, Hoekstra Y, Kamman RL, et al. Specific MR imaging of human lymphocytes by monoclonal antibody-guided dextran-magnetite particles. Magn Reso Med. 1992;25(1):148-157.

11. Knauth M, Egelhof T, Roth SU, R. Wirtz C, Sartor K. Monocrystalline iron oxide nanoparticles: possible solution to the problem of surgically induced intracranial contrast enhancement in intraoperative MR imaging. ANJR Am J Neuroradiol. 2001;22:99-102.

12. Vogl TJ, Hammerstingl R, Schwarz W, et al. Superparamagnetic iron oxide - enhanced versus gadolinium-enhanced MR imaging for differential diagnosis of focal liver lesions. Radiology. 1996;198(3):881-887.

13. Clément O, Siauve N, Cuenod CA, Frija G. Liver imaging with ferumoxides (Feridex): fundamentals, controversies, and practical aspects. Top Magn Reson Imaging. 1998;9(3):167-182.

14. McLachlan SJ, Morris MR, Lucas MA, et al. Phase I clinical evaluation of a new iron oxide MR contrast agent. J Magn Reson Imaging. 1994; 4(3):301-307.

15. Li W, Tutton S, Vu AT, et al. First-pass contrast-enhanced magnetic resonance angiography in humans using ferumoxytol, a novel ultrasmall superparamagnetic iron oxide (USPIO)-based blood pool agent. J Magn Reson Imaging. 2005;21(1):46-52.

16. Reimer P, Marx C, Rummeny EJ, et al. SPIO-enhanced 2D-TOF MR angiography of the portal venous system: Results of an intraindividual comparison. J Magn Reson Imaging. 1997;7(6):945-949.

17. Daldrup-Link HE, Kaiser A, Helbich T, et al. Macromolecular contrast medium (feruglose) versus small molecular contrast medium (gadopentetate) enhanced magnetic resonance imaging: differentiation of benign and malignant breast lesions. Acad Radiol. 2003;10(11):1237-1246.

18. Taupitz M, Wagner S, Schnorr J, et al. Phase I clinical evaluation of citrate-coated monocrystalline very small superparamagnetic iron oxide particles as a new contrast medium for magnetic resonance imaging. Invest Radiol. 2004;39(7):394-405.

19. Passirani C, Barratt G, Devissaguet J-P, Labarre D. Long-circulating nanopartides bearing heparin or dextran covalently bound to poly(methyl methacrylate). Pharm Res. 1998;15(7):1046-1050.

20. Giammona G, Carlisi B, Palazzo S. Reaction of $\alpha, \beta$-poly(Nhydroxyethyl)-DL-aspartamide with derivatives of carboxylic acids. J Poly Sci Pol Chem. 1987;25(10):2813-2818.

21. Giammona G, Cavallaro G, Fontana G, De Guidi G, Giuffrida S. Macromolecular prodrug of diflunisal. II. Investigations of in vitro release and of photochemical behaviour. Eur J Pharm Sci. 1996;4(5):273-282. 
22. Giammona G, Puglisi G, Cavallaro G, Spadaro A, Pitarresi G. Chemical stability and bioavailability of acyclovir coupled to $\alpha, \beta$-poly $(\mathrm{N}$ 2-hydroxyethyl)-dl-aspartamide. J Control Release. 1995;33(2): 261-271.

23. Hayashi T, Iwatsuki M. Biodegradation of copoly(L-aspartic acid/Lglutamic acid) in vitro. Biopolymers. 1990;29(3):549-557.

24. Jain GL, Ray AR. Syntheses and characterization of random copolymers of aspartic acid with lactic acid and glycolic acid. Die Makromolekulare Chemie. 1981;182(10):2557-2561.

25. Jeong SY, Kim H, Kwak B-K, et al. Biocompatible Polyhydroxyethylaspartamide-based Micelles with Gadolinium for MRI Contrast Agents. Nanoscale Research Letters. 2010;5(12):1970-1976.

26. Yoon S-W, Chung DJ, Kim J-H. Preparation and swelling behavior of biodegradable hydrogels based on $\alpha, \beta$-poly(N-2-hydroxyethyl-DLaspartamide). J Appl Polym Sci. 2003;90(13):3741-3746.

27. Giammona G, Carlisi B, Pitarresi G, Cavallaro G, Liveri VT. Water-soluble copolymers of an antiviral agent: synthesis and their interaction with a biomembrane model. J Control Release. 1992;22(3): 197-204.

28. Cho SH, Shin BC, Yuk SH, et al, inventors. Multifunctional contrast agent using biocompatible polymer and preparation method. Korean patent KR 10-2009-0020676; Publication number WO/2010/104253. September 16, 2010.

29. Stark DD, Weissleder R, Elizondo G, et al. Superparamagnetic iron oxide: clinical application as a contrast agent for MR imaging of the liver. Radiology. 1988;168:297-301.

30. Weissleder R, Stark DD, Engelstad BL, et al. Superparamagnetic iron oxide: pharmacokinetics and toxicity. AJR Am J Roentgenol. 1989; 152(1):167-173

31. Hamm B, Staks T, Taupitz M, et al. Contrast-enhanced MR imaging of liver and spleen: first experience in humans with a new superparamagnetic iron oxide. J Magn Reson Imaging. 1994;4(5):659-668.

32. McLachlan S, Morris M, Lucas M, et al. Phase I clinical evaluation of a new iron oxide MR contrast agent. J Magn Reson Imaging. 1994;4(3): 301-307.

33. Reimer P, Balzer T. Ferucarbotran (Resovist): a new clinically approved RES-specific contrast agent for contrast-enhanced MRI of the liver: properties, clinical development, and applications. European Radiology. 2003;13(6):1266-1276.

34. Wang J, Chen Y, Chen B, et al. Pharmacokinetic parameters and tissue distribution of magnetic $\mathrm{Fe} 3 \mathrm{O} 4$ nanoparticles in mice. Int $J$ Nanomedicine. 2010;5:861-866.
35. Pouliquen D, Le Jeune JJ, Perdrisot R, Ermias A, Jallet P. Iron oxide nanoparticles for use as an MRI contrast agent: pharmacokinetics and metabolism. Magn Reson Imaging. 1991;9(3):275-283.

36. Ma HL, Xu YF, Qi XR, Maitani Y, Nagai T. Superparamagnetic iron oxide nanoparticles stabilized by alginate: pharmacokinetics, tissue distribution, and applications in detecting liver cancers. Int J Pharm. 2008;354(1-2):217-226.

37. Iversen NK, Frische S, Thomsen K, et al. Superparamagnetic iron oxide polyacrylic acid coated $\gamma-\mathrm{Fe}_{2} \mathrm{O}_{3}$ nanoparticles does not affect kidney function but causes acute effect on the cardiovascular function in healthy mice. Toxicol Appl Pharmacol. 2013;266(2):276-288.

38. Caliceti P, Quarta SM, Veronese FM, Cavallaro G, Pedone E, Giammona G. Synthesis and biopharmaceutical characterisation of new poly(hydroxyethylaspartamide) copolymers as drug carriers. Biochim Biophys Acta. 2001;1528(2-3):177-186.

39. Arruebo M, Fernández-Pacheco R, Ibarra MR, Santamaria J. Magnetic nanoparticles for drug delivery. Nano Today. 2007;2(3):22-32.

40. Bulte JWM, Kraitchman DL. Iron oxide MR contrast agents for molecular and cellular imaging. NMR Biomed. 2004;17(7):484-499.

41. Renshaw PF, Owen CS, McLaughlin AC, Frey TG, Leigh JS. Ferromagnetic contrast agents: a new approach. Magn Reson Med. 1986;3(2):217-225

42. Crosby WH. Normal functions of the spleen relative to red blood cells: a review. Blood. 1959;14(4):399-408.

43. Laurent S, Forge D, Port M, et al. Magnetic iron oxide nanoparticles: synthesis, stabilization, vectorization, physicochemical characterizations, and biological applications. Chem Rev. 2008;108(6):2064-2110.

44. Corot C, Robert P, Idée J-M, Port M. Recent advances in iron oxide nanocrystal technology for medical imaging. Adv Drug Deliv Rev. 2006;58(14):1471-1504.

45. Weissleder R, Elizondo G, Wittenberg J, Rabito CA, Bengele HH, Josephson L. Ultrasmall superparamagnetic iron oxide: characterization of a new class of contrast agents for MR imaging. Radiology. 1990;175:489-493.

46. Park SH, Pradeep K. Absorption, distribution, excretion, and pharmacokinetics of ${ }^{14} \mathrm{C}$-pyronaridine tetraphosphate in male and female Sprague-Dawley rats. J Biomed Biotechnol. 2010;2010:590707.

47. Schümann K, Schäfer SG, Forth W. Iron absorption and biliary excretion of transferrin in rats. Res Exp Med (Berlin). 1986;186(3):215-219.

48. Hahn PF, Bale WF, Hettig RA, Kamen MD, Whipple GH. Radioactive iron and its excretion in urine, bile, and feces. J Exp Med. 1939;70(5): $443-451$.
International Journal of Nanomedicine

\section{Publish your work in this journal}

The International Journal of Nanomedicine is an international, peerreviewed journal focusing on the application of nanotechnology in diagnostics, therapeutics, and drug delivery systems throughout the biomedical field. This journal is indexed on PubMed Central,

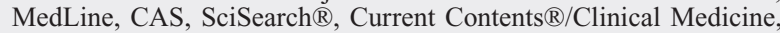

\section{Dovepress}

Journal Citation Reports/Science Edition, EMBase, Scopus and the Elsevier Bibliographic databases. The manuscript management system is completely online and includes a very quick and fair peer-review system, which is all easy to use. Visit http://www.dovepress.com/ testimonials.php to read real quotes from published authors. 